\title{
HRD and Organizational Change: Evidence-Based Practice
}

\author{
Bob Hamlin, University of Wolverhampton, UK
}

\begin{abstract}
Most HRD practitioners are, or wish to become, actively involved as strategic business partners of managers, particularly with respect to helping them bring about effective and beneficial organizational change within their own organizations, or within host organizations. This article discusses the complexities of HRD related process issues in the effective management of organizational change, and the value of using HRD-related theory, change management-related theory, and/or academically rigorous internal in-company research to help inform, shape, and evaluate the change agency practice of HRD professionals and the managers they partner. Following a discussion of why many organizational change programmes fail, the author argues that 'evidencebased HRD' geared to the strategic thrust of the business will likely lead to the HRD function maximizing its contribution to organizational effectiveness and sustainable business success. Two UK case examples of evidence-based HRD are presented, followed by a discussion of the worth of 'professional partnership' research and empirical generalization 'replication' research.
\end{abstract}

\section{Introduction}

This article has three aims. The first is to highlight the critical role that HRD practitioners could or should play as strategic business partners of managers in the management of organizational change (OC), and the concomitant necessity of robust change management enhancing research. The second is to present evidence supporting the case for HRD practitioners and managers to consider investing in context-specific OC-related research within their own organizations in order to improve their change-agency effectiveness; and to consider conducting such research in collaboration with academics within 'professional partnership' arrangements to ensure the rigour, robustness, and reliability of the findings. The third aim is to argue the case for empirical generalization 'replication' research that focuses on context-general OC-related field problems experienced in multiple specific organizational settings, and/or across organizational sectors and nations, in support of evidence-based HRD and evidence-based organizational change-agency practice. Stewart (2015) has argued that HRD practitioners are change agents who help and partner with managers in the facilitation of organizational change programmes within their own or host organizations. Together with other writers, Stewart claims that HRD is a strategic function that can have a significant impact on the long term business success of organizations (see Stewart and McGoldrick, 1996; Fredericks and Stewart, 1996). Furthermore, Gold, Holden, Iles, Stewart and Beardwell (2009) argue that HRD in practice and theory has a major influence on the interplay of leadership, culture, and employee commitment through: (i) helping to develop current and future leaders; (ii) involvement in shaping the organizational culture; (iii) building commitment among organization members; and (iv) anticipating required managerial responses to changing conditions. Similarly, McKenzie, Garavan and Carbery (2012) observed that "the shift from operational and tactical HRD to strategic HRD has witnessed a metamorphosis for HRD practitioners increasingly becoming partners in the business tasked with aligning people, strategy, and performance rather than simply promoting learning and development" (p.354). This observation echoes Kohut and Roth's (2015) claim that "HRD practitioners and scholars need 
to enter the fray of the discussion on change management" (p.231). Over the last three decades of the twentieth century, the need for managers to initiate and facilitate organizational change management programmes effectively and beneficially has continued to increase in frequency, pace, and complexity (see Hamlin, Keep and Ash, 2001). In this context a major challenge facing modern day HRD practitioners is how best to help their colleague managers in this endeavour. Unfortunately, many OC programmes fail because both managers and HRD professionals find themselves unable to rise to the challenge that change brings. Consistent with the three aims outlined above, this article addresses the problematic issue of bringing about strategic organizational change successfully. It does so by discussing and illustrating the contribution that good collaborative replication HRD research can make in support of HRD and organizational change agency practice. The specific purposes are as follows:

(i) To discuss the reasons why organizational change programmes fail.

(ii) To make the case that HRD practitioners and managers should become evidence-based in their organizational change agency practice.

(iii) To outline certain obstacles to 'evidence-based HRD', 'evidence-based management' and 'evidence-based organizational change agency'.

(iv) To discuss how these obstacles may be overcome through HRD 'professional partnership' research and empirical generalization 'replication' research, respectively.

\section{Why Do Organizational Change Programmes Fail?}

The success rate of planned organizational change strategies over the past 30 years has been dismal with two thirds or more OC programmes having failed to achieve their intended aims (Burnes, 2004; Choi and Ruona, 2011; Szabla, 2007). This failure is surprising bearing in mind the plethora of advice and guidance on the 'how to' of change management. Most change management models on offer follow Lewin's 'unfreeze-move-refreeze' process, and although they differ in varying ways, all include a common 'step by step' approach as depicted in a generic 'composite' model offered by the author (see Hamlin, 2001a; Hamlin, 2002). The model is comprised of six steps as follows:

Stage 1 Diagnose/explore the present state and identify the required future state.

Stage 2 Create a strategic vision.

Stage 3 Plan the change strategy.

Stage 4 Secure ownership, commitment and involvement including top management support.

Stage 5 Project manage the implementation of the change strategy and sustain momentum.

Stage 6 Stabilize, integrate and consolidate to ensure perpetuation of the change.

It is assumed that HRD practitioners and managers possess the requisite knowledge, attitude, and skills to apply the model effectively. However, according to Shook and Roth (2011) the failure rate of organizational change programmes is around $70 \%$ irrespective of whether they are driven by 'mergers', 'acquisitions', 'downsizing', 'de-layering', 'IT', 'total quality management', 
'business process re-engineering', or 'culture change' initiatives, and this failure rate suggests they do not. Based on his review of organizational change management studies from various researchers in the US, the UK, and in various other European countries, the author identified over 15 years ago six underlying root causes or 'failings' of managers and HRD practitioners which explain in part why OC programmes fail (Hamlin, 2001a). Five of these failings relate to managers:

Failing 1 Managers not knowing the fundamental principles of change management.

Failing 2 Managers succumbing to the temptations of the 'quick fix' or 'simple solution.

Failing 3 Managers not fully appreciating the significance of the leadership and cultural aspects of change.

Failing 4 Managers not appreciating sufficiently the significance of the people issues.

Failing 5 Managers not knowing the critical contribution that the HRD function can make to the management of change.

Failing 6 Trainers and developers lacking credibility in the eyes of line managers.

Regarding Failing 5, many managers regard training and development as an undesirable cost that can only be afforded when profits and/or funding are plentiful, rather than as an investment which the organization can ill-afford not to make even in the toughest of times, and especially during periods of transformational change. Yet if managers are to be in control of change they must ensure they are in control of the knowledge, attitude and skill issues associated with change itself. This means giving sufficient time and attention to the 'soft' people-oriented HRD aspects of the change management process. Regarding Failing 6, for decades many if not most HRD practitioners have lacked high 'credibility' with line managers. For some this has not been helped by being part of HR departments which have also lacked status due to: (i) the dominant focus on personnel administration, and (ii) line managers being frustrated by HR staff who show little understanding of business, are too rigid, and who invariably seem to say 'no' when managers need their help to find ways to make things work (Hamlin, 2001a; Cardillo, 2012). Thus, managers place low role expectations on most HR professionals (Thornhill, Lewis, Millmore, and Saunders; 2000; Ulrich, 1997), and by association also on HRD professionals. Additionally, this lack of credibility can be exacerbated in countries such as the USA where HRD-related postgraduate professional qualifications programmes offered by universities are predominantly delivered by Schools of Education, rather than by Schools of Business or Management as in the UK. In those countries HRD professionals are often perceived more as 'adult educationalists' or 'specialized teachers', rather than as 'people and organization development consultants'. Consequently, it behoves HRD practitioners to concern themselves with the mainstream business and management of organizations if they are to maximize their contribution to organizational effectiveness and sustainable business success (see Stewart and Hamlin, 1990).

The way of achieving this is to engage in a change management process by: (i) conducting organization wide 'health' checks to identify required changes and the associated learning and development needs of managers and non managerial employees at the organizational, group, and individual level, (ii) providing 'expert' advice on how best to meet these needs; (iii) recommending or taking the requisite action, and/or responding to needs resulting from 'top down' OC initiatives; and (iv) developing the skills and abilities of managers to manage change 
effectively and to cope effectively with any unintended consequences of the planned changes. However, much depends on the extent to which they can improve their 'credibility' in the eyes of line managers. Hence, HRD practitioners need to 'sell' their potential as valued strategic business partners of managers and in particular the distinctive contribution they can make in formulating and implementing organizational change programmes.

\section{Evidence-Based HRD and Organizational Change}

The notion that HRD is a strategic function and that HRD practitioners are agents of change who work in strategic business partnership with line managers is consistent with Phillips and Shaw's (1989) call for trainers to develop into the roles of 'training consultant, 'learning consultant' and 'organization change consultant'. However, as previously argued by the author, to become truly expert, HRD practitioners need to use the findings of high quality management-related and HRD-related research to inform, shape, and evaluate the effectiveness of their consultancy and change agency practice (Hamlin, 2001). The author and other writers have since reinforced this view by arguing that they need to reflect critically and become evidence-based (Hamlin, 2007; Holton, 2004; Kearns, 2014). Similarly, calls have been made for managers to enhance their professional practice by becoming research-informed and evidence-based (see Axelsson, 1998; Briner, Denyer and Rousseau, 2009; Latham, 2009, Pfeffer and Sutton, 2006; Rousseau, 2006, 2012; Stewart, 1998). Drawing upon evidence-based practice approaches in other fields, the types of 'best evidence' that could be used to support evidence-based human resource development could, and in the author's view should, include: (i) Mode 1 research which is about testing theory and generating conceptual knowledge, (ii) Mode 2 research which is about generating instrumental knowledge to resolve real-life/work-based problems, and in some cases developing mid-range theory, and (iii) descriptive studies or the consensus view of a body of field experts. As in medicine, 'best evidence' does not need to be comprised solely of findings from positivist 'normal science' studies (Kuhn, 1996, p.5). Indeed, findings from any type of good quality research can be used, whether quantitative or qualitative. Such studies may be based either (i) on the paradigmatic assumptions, methodologies, and methods privileged by any one of the main research paradigms, namely: 'Positivism/Functionalism'; 'Post positivism/Radical structuralism'; 'Critical-idealogical/Radical humanism' and 'Constructivism-interpretivism', or (ii) on the philosophical assumptions associated with pragmatism and Morgan's (2007) 'pragmatic approach' which allows the researcher to adopt whichever paradigmatic assumptions are considered best for achieving the research objectives (see also Hamlin, 2015). In addition, the on-going findings and insights on practice gained from action research can also be considered as a form of 'best evidence'.

An important feature of evidence-based change agency is the notion of critical reflection. For the author, the significance of this notion was reinforced 15 years or so ago by the 'reflections on practice' case histories' of 18 of his MSc in HRD and Organizational Change alumni, all of whom were HRD practitioners who, as part of their MSc programme at the University of Wolverhampton-UK, had helped managers within their own organization or in a host company to bring about effectively and beneficially an identified desired strategic organizational change (see Hamlin, Keep, and Ash, 2001). Some of them had incorporated action research as an integral component of the facilitated change management process. The insights gained from their respective 'reflective case histories' led the author to offer a definition for what he called 'research-informed HRD'. 
Research-informed HRD is the conscientious and explicit use of research findings and the research process to inform, shape, measure and evaluate professional practice (Hamlin, 2002: p.98).

That HRD practitioners and also the managers they help should become 'critically reflective' and 'evidence-based' is compelling, particularly bearing in mind the increasing paradoxes, contradictions, and complexities of organizational life which complicate the task of facilitating OC programmes efficiently and effectively (Hatton, 2001; Vince, 2014). This should involve taking action to (i) make sense of the organization and understand better what is going on; (ii) develop suitable OC strategies; (iii) implement these OC strategies effectively; (iv) critically evaluate the change process and its effectiveness; and (iv) draw lessons for the future by reflecting critically upon their individual practice as agents of change.

Some writers suggest the tasks associated with change management processes are usually obvious, and that there is nothing intellectually demanding or difficult about the management of organizational change (Rogers, Shannon, and Gent, 2003). However, people and organizations are far more complex than is often inferred from much of the change management literature. Furthermore, the many 'solutions' offered for resolving organizational change management 'problems' can be more difficult to comprehend and implement than is often claimed by 'experts'. Hence, evidence-based HRD practitioners working with colleague managers would do well to use not only the generalized 'conceptual knowledge for understanding' that emerges from the findings of conventional Mode 1 research, but also to instigate and/or collaboratively conduct internal Mode 2 research in order to generate instrumental knowledge for action that has optimum relevance and utility. Engagement in good quality Mode 2 applied research is likely to lead to a better understanding of the particular complexities, contradictions, and paradoxes that may affect or are affecting the change management processes and the effectiveness of the change agency practice. They would also do well to consider building into their change management processes sufficient time for critical reflection. From such reflection new theoretical insights may emerge which can explain the success or failure of particular aspects of their OC programme. Informed by a critical review of their own change agency contribution, 'new ways' and 'lay theories' for approaching problems of change confronting them may also emerge. The practical significance of in-house Mode 2 research to solve context-specific work-based problems should not be underestimated.

In summary, HRD practitioners and managers who use good Mode 1 and/or Mode 2 research to inform, shape, and evaluate their change agency practices are more likely to be effective in bringing about beneficially planned organizational change that delivers the intended desired endstate outcomes, instead of the more usual undesired and/or unintended outcomes. However, a major obstacle to becoming evidence-based is the continuing sparseness of 'best evidence' that can be drawn upon to support evidence-based management and HRD practice.

\section{What Types of Research Are Useful in Support of Evidence-Based HRD and Organizational Change?}

The challenges of becoming an 'evidence-based practitioner' are discussed in this section, including the need to determine the types of research topics and approaches that are most likely to be of greatest utility to evidence-based HRD practitioners and line managers seeking to improve their change agency practice. Of importance to all organizational change agents is the need to understand in sufficient depth the people and organization related factors that need to 
be improved and changed, including critical aspects of the prevailing organizational culture, management culture, and leadership that can either help or hinder the organizational change management process. The small body of existing 'best evidence' can provide valuable contextgeneral knowledge to inform the formulation of a change strategy, regardless of the specificities of a particular organizational setting. For example, various researchers have explored 'employee resistance to change' (see Garcia-Cabrera, and Hernandez, 2014; Szabla, 2007) and 'employee readiness for change' (see Choi and Ruona, 2011); whilst others have explored the related issue of organizational dynamics that can impact positively or negatively on the organizational change process. For instance, Vince (2014) investigated the specific issues of emotion, power relations, and political dynamics which are factors that can enhance or inhibit learning and development, and thereby support or undermine the effectiveness of the planned OC programme.

Extant generalized knowledge can help only so far in identifying and understanding better the many paradoxes, contradictions and complexities that limit the success of so many OC programmes. Hence, HRD practitioners and managers should consider commissioning and/or conducting context-specific/case-specific internal research as part of their change agency. When conducted with academic rigour, such OC related research can lead to deep seated fundamental issues about the running of the organization being surfaced and confronted. Examples might include those ineffective aspects of managerial/organizational culture, or specific managerial and employee behaviour that impede or block innovation and change. The results of internal research projects that are recognized by people within the organization as being relevant, rigorous, and of a high ethical standard, are likely to 'strike a chord'. As a result, both managers and non-managerial employees are more likely to accept the evidence of ineffective features of organizational life that impact negatively, or are likely to impact negatively, on the OC process, including their own individual performance or behavioural deficiencies. Additionally, they are more likely to advance personal opinions, reactions, and 'theories' that would otherwise not be revealed. This type of research can generate the 'hard' empirical evidence required to reveal and accurately reflect back to the organization the truth and realities of organizational life, and thereby help surface organizational taboos or latent and un-discussed sensitive issues that should be addressed (Bruce and Wyman, 1998; Pfeffer and Sutton, 2006). Engaging with and using such research can enable HRD practitioners and managers to become fully effective as evidencebased change agents.

\section{Overcoming the Obstacles to Evidence-Based HRD and Organizational Change}

As previously mentioned, there is a paucity of generalized HRD-related research that can unreservedly be translated and transferred to organizations, organizational sectors, or countries beyond the original location of the study. Therefore, until this deficiency of Mode 1 researchgenerated theory is rectified over time by HRD scholars, HRD practitioners and colleague managers wishing to operate as evidence-based change agents will, out of sheer necessity, have to instigate and/or engage with Mode 2 research within their own organizations. The results of such research can then be used to inform, shape and critically evaluate the way they practice as agents of change. As well as action research and also critical action learning which Vince (2008) and other writers advocate, the author has personally experienced the merits of 'professional partnership' research and empirical generalization 'replication' research. The relevance, utility, and value of both of these approaches to research are discussed and illustrated next. 


\section{Professional Partnership Research}

According to Jacobs (1997) 'professional partnership' research is carried out between a university and a collaborating organization with scholars and practitioners jointly conducting programmes of research that are focused on work-based problems of concern to management. However, in doing so they operate with their own mutually exclusive yet complementary goals. Of critical importance is the need to maintain the integrity of both sets of goals for the common good. A dual goal at the very outset of the study is to strive to generate empirical evidence that can be used reliably to help bring about required change within the organization through the application of academically rigorous research, whilst at the same time generating new insights capable of advancing knowledge in the field of HRD and management. Depending upon the particular focus and purpose of the research, the results may be used to inform the OC programme design, and/or to evaluate it prior to a redesign that may be required at each iterative stage of the planned change management process until the desired end-state has been reached. The author has participated as the HRD scholar partner within several professional partnership research studies in various UK public, private, and third (non-profit) sector organizations. These were either instigated by him or the respective HRD practitioner partner. The results of all of these studies have been reported in various academic journals and/or at international research conferences held in Europe and North America. Each study generated instrumental knowledge that the respective HRD practitioner partners subsequently used directly or indirectly to inform and shape an HRDrelated intervention, or to critically evaluate an aspect of HR or management policy and practice within their respective organizations. Two case examples of this type of collaborative inquiry are presented below to illustrate the nature and impact of 'professional partnership' research. The respective research focus and goal, and where the results of the study have been published, are described briefly. In addition, and in both cases, the practical relevance and impact of the research within the two respective collaborating organizations are illustrated though 'testimonial evidence' provided by the respective HRD practitioner partner or partners.

\section{Case Testimonial 1}

\section{HM Customs and Excise: (Anglia Region)}

This collaborative replication study of perceived managerial and leadership effectiveness was commissioned by the Collector (Executive Head Dick Shepherd) of the Anglia Region of HM Customs and Excise-a major department of the British Civil Service. The study was carried out jointly by the author and Dick Shepherd's Research Officer (and OD Consultant) - Margaret Reidy who respectively acted as the HRD scholar and HRD practitioner in the partnership. The research took place from 1994 to 1998, during which period Margaret Reidy was also undertaking a parallel programme of qualitative ethnographic longitudinal doctoral research on cultural change. Details of this replicated managerial behaviour research, and the impact of applying the results in practice, have been published in several conference proceedings and academic journals (see Hamlin, Reidy, \& Stewart, 1998; Hamlin, \& Reidy, 2005).

\section{Extract from Personal Testimonial of Dick Shepherd}

I was accountable to the Board of Customs and Excise for achieving operational targets within the region. To cope with the demands for ever-increasing outputs and for more openness in our dealings with the public I needed to change the culture of the organization. I used seminars, walking the floor, publishing my Expectations document and was making progress and lifting 
outputs. But I felt that I did not really know how deep the changes were penetrating - there was always an element of telling me what I wanted to hear in the feedback I was receiving. I commissioned the critical incident/factor analytic research [on managerial and leadership effectiveness] from Bob Hamlin at Wolverhampton University, [and it was] my initial hope to find the patterns of strengths and weaknesses among the managers and team leaders. The results exceeded my expectations for I felt I was getting the real behaviours and attitudes prevalent in all the various parts of the organization for the first time. I was able to use the emerging results very quickly at my annual management conference where it made a big impact. This was no consultant's abstract interpretation using the latest business management technique. This was real. This was us. I had a profile of the attitudes and behaviours in the organization for the first time based on fact rather than intuition. A key factor right through this whole process was the close partnership between me and the research team. The clear understanding was that the research should be carried out independently with rigour and integrity to as high an academic quality as was necessary to provide provable results. My part was to commission it, facilitate its freedom in operation, and ensure that the [research process and] results were directly related to the working life of the Department. In fact the research team went on to develop a set of (management) competencies that we were able to use in our local appraisal system to improve managerial effectiveness. They also developed specifically targeted team building and managerial effectiveness workshops.

\section{R.C. Shepherd}

Date: 21 May 2002

\section{Extract from Personal Testimonial of the HRD Practitioner Partner - Margaret Reidy}

The data that resulted from the professional partnership-research "was so rich that its preliminary findings were immediately and effectively used by Dick Shepherd and me to inform and shape a number of OCD/HRD interventions for managing the (organizational) change, including workshops and local initiatives" ... "The preliminary findings helped people to assess their behaviours and attitudes in newer and more in-depth ways". This was invaluable to the everyday work of the organization as managers could effectively identify and curtail or harness those behaviours (associated with effective or ineffective management respectively). This was achieved with the support of [OD/HRD] tools developed from the research findings to improve the rapidly transforming organization. The finalized data took this further. As a direct result of the managerial [and leadership] effectiveness research, a new set of behavioural management competencies were developed exclusively for the organization" ... "The findings of the overall research [i.e. the ethnographic 'cultural change' study and replication 'managerial behaviour' study], that were both positive and negative in terms of people's attitudes and behaviours, were accepted in a highly positive manner by the (Anglia) people. The reason for acceptance was because the research had been conducted in an impartial and objective manner, and names were never used. This created, on the whole, trust between the interviewers and the interviewees and elicited interest and co-operation in the research on a wide scale". Over the four years of study and practical application "the research found that the culture was adapting and changing in a very real and measurable sense. This was reassuring for the management (in particular for Dick Shepherd) who had doubted that cultural change could be effectively measured. The research also helped to prove to management that an in depth knowledge of their organizational culture was one of the most effective tools in organizational change. It became understood that cultural change was not a 'soft issue', but an integral practical issue with very real rewards in bringing about successful organizational change".

Margaret Reidy Date: June, 2002 
It should be noted that both cases are replication studies of perceived managerial and leadership effectiveness using the same research design, methodology and method as adopted in the previous replication studies cited above. As will be appreciated, the findings of the HM Customs and Excise (Anglia Region) case were used in support of an evidence-based OC initiative designed to improve the organization's managerial culture, whereas the findings of the 'TLFN' case were used to guide a specific evidence-based HRD initiative concerned with executive leader development. In both cases, the academic credentials of the findings resulting from the 'professional partnership' studies contributed greatly to the research being accepted as relevant, reliable, applicable, and useful by people within the two respective organizations. A highly significant lesson learned from these two cases is that HRD initiatives informed by empirical evidence derived from good internal ('home grown') academically rigorous research-the results of which managers and employees find hard to discount or ignore-are likely to be more effective than initiatives guided by 'prescriptive solutions' offered in textbooks or by outside consultants.

\section{Case Testimonial 2}

\section{TLFN Group plc}

The organization in which this collaborative professional-partnership research took place is a large UK-based multi-national retail telecommunications company which is referred to as TLFN Group PLC. The aim was to explore managerial culture at the executive leader level of the company to gain a better understanding of it. The results and their application have been published in a management related academic journal (see Hamlin \& Sawyer, 2007).

\section{Personal Testimonial of the HRD Practitioner Partner - Jenni Sawyer}

The trigger for this research was the need to conduct a research project as part of the MSc in HRD and Organizational Change study programme that I was undertaking at the University of Wolverhampton Business School. At the time I was employed within the HR department of TLFN Group PLC. I chose to conduct a replication study of 'managerial and leadership effectiveness', and I found the extensive experience and knowledge gained through the process of selecting this research topic and methods of great benefit when it came to building a business case for conducting the research within my organization. This was a highly commercial environment, so it was important that I was able to demonstrate a projected return on that investment in time and resource. Following the identified need for a 'one-company' organizational and management approach, we needed to acquire a better understanding of the evolving culture within our UK business, as reflected by the behaviour of senior people. The key aim was to identify a set of behavioural criteria of managerial and leadership effectiveness that reflected 'best practice' within the company. The findings of the research challenged various aspects of the existing companywide competency framework and raised a number of important questions to be explored. Most significantly 'customer focus' was found to be so core to the culture and values that the associated behaviours had become inherent and were therefore no longer recognised by senior people as indicators of managerial and leadership effectiveness. The findings were used to inform and shape the ongoing development of the company's Executive Leader Development Programme. This research-informed programme was then planned to be applied across Europe.

Jenny Sawyer Senior HR Manager: TLFN Group plc (when the research took place)

Date 25 October 2013 


\section{Replication Research}

The author's long term goal when engaging as the HRD scholar partner in the two illustrative cases outlined above, and also in all previous and subsequent replication studies, has been to search for evidence of universalistic or generic behavioural criteria of perceived managerial and leadership effectiveness. The approach used has been informed by the notion of derived etic research (Berry, 1989) which is based on replication logic and multiple cross case comparative analysis (Eisenhardt, 1989). Consequently, each newly instigated replication study has replicated as closely as possible an earlier replication study carried out in the same organizational sector, thereby maximizing the comparability of the generated findings. This type of inquiry is consistent with what Tsang and Kwan (1999) have referred to as empirical generalization replication research, in which the same phenomenon experienced in multiple contexts is explored using the same research focus, philosophical perspective, methodology, and methods in order ultimately to develop mid-range theory. It is also consistent with van Aken's (2009) notion of design science in the field of management. This type of research is primarily aimed at developing 'general substantive and procedural design science' to solve common 'field problems' within a particular discipline/field. However, van Aken claims the notion can also be used in the explanatory sciences to develop 'general solution concepts' and mid-range theory that can be used in multiple organizational contexts beyond the ones where the empirical research has been carried out; albeit limited in validity to that particular applied field or domain of practice (van Aken, 2007). For a more detailed explanation of design science and HRD research see Sadler-Smith (2015). Using the findings from the two cases illustrated above, together with the author's replication studies in other organizations, Hamlin and Hatton (2013) have identified through multiple cross-case and cross-sector comparative analysis an emergent British taxonomy of perceived managerial and leadership effectiveness. Similarly, Patel and Hamlin (2012) have identified an emergent EU related taxonomy derived from replication studies in Germany, Romania and the UK. Both taxonomies could be used as 'best evidence' to support HRD intervention in various organizations similar to those outlined in the above illustrative case testimonials. Additionally they could be used by management and leadership development (MLD) practitioners to maximize their contribution to improving organizational effectiveness and performance through planned initiatives focused on the training and development of managers and leaders. Such evidencebased MLD interventions are more likely to result in the development of the style of 'leadership' and type of 'culture' that are most likely to be conducive to learning and effective organizational change agency, than those that typically persist following investment in conventional MLD programmes.

\section{Discussion}

The prime message of this article for HRD practitioners and HRD scholars is that by becoming critically reflective and evidence-based by using research to inform and evaluate practice, and by engaging in 'professional partnership' research, they will more likely: (i) make an important and valued contribution to the bridging of the much discussed 'research-practice gap' in the fields of HRD and management, and (ii) maximize their contribution to organizational effectiveness and long term business success. However, these contributions are unlikely to become a reality for HRD practitioners unless: (i) they can help line managers to overcome the five OCD 'failings' outlined earlier in this article, and (ii) they take the necessary steps to improve significantly their 'credibility' with managers so that they become welcomed as strategic business partners. 
Herein lies a major challenge for MLD and other HRD practitioners who train, develop, and coach/mentor managers, and also for HRD scholars in universities who teach on management and HRD-related professional qualification programmes such as Master level degree courses in management, leadership, organizational change, OD, and HRD (see Hamlin, 2002). Hence, to increase their impact and effectiveness this author suggests that HRD scholars should consider: (i) incorporating 'evidence-based practice' into their everyday teaching; and (ii) being more open to Mode 2 research conducted in collaboration with HRD practitioners - rather than engaging solely with Mode 1 research. In so doing, it is recommended that they consider focusing some of their research effort into studying specific work-based 'research problems' of particular interest to managers and HRD practitioners in multiple organizations, sectors or even countries (what van Aken (2007) refers to as design science 'field problems') and for such studies to be conducted in 'professional partnership' arrangements whenever possible. Additionally, HRD scholars might also consider adopting 'replication (empirical generalization) research' approaches in partnership with HRD scholars in other universities and/or in other countries, for the purpose of exploring a particular 'field problem' that engages their common interest. In so doing, their joint aim would be the identification of geocentric/context-general concepts and constructs, and if possible the development of universalistic theories through 'replication logic' and 'multiple crosscase comparative analysis'. An important message for top managers and business/organizational leaders resulting from the case for 'professional partnership' and 'replication' research presented in this article is that they are more likely to grow and optimize organizational capability and flexibility in a context of ongoing change, and thereby create high performance organizations that deliver sustainable business success if they: (i) give greater consideration to the 'soft' stuff of management when formulating organizational change strategies; (ii) allow line managers who implement the OC strategies to have sufficient time to attend to the 'soft' human side issues involved in the change management process; (iii) give recognition to the value of evidence-based management and evidence-based HRD approaches in bringing about effective and beneficial strategic organizational change and development: and (iv) sponsor 'professional partnership' research projects focused on 'real-live' organization-based problems or issues of concern.

In conclusion, this author strongly urges HRD professionals and line managers who wish to maximize their contribution to the effective and beneficial facilitation of organizational change (and development), to give serious consideration to the concepts of evidence-based HRD and evidence-based management.

\section{References}

Axelsson, R. (1998). Towards an evidence-based healthcare management. International Journal of Health Planning and Management, 13 (4), 301-317.

Beer, M., and Nohria, N, (2000). Cracking the code of change. Harvard Business Review, 78, 133-141.

Berry, J. W. (1989). Imposed etics-emics-derived etics: The operationalization of a compelling idea. International Journal of Psychology, 24, 721-735.

Brewerton, P., and Millward, L. (2001). Organizational Research Methods. London: Sage.

Briner, R., Denyer, D., and Rousseau, D. (2009). Evidence-based management: Concept clean-up time? Academy of Management Perspectives, 23, 19-32.

Bruce, R., and Wyman, S. (1998). Changing organizations: Practicing action training and research. Thousand Oaks, CA: Sage.

Burnes, B. (2004). Managing change: A Strategic approach to organizational dynamics. London: Prentice Hall. 
Cardillo, S. (2012). The HR professional's role in building organizational success. Kingston, Ontario, Canada: Queen's University IRC. http://irc.queensu.ca/articles/hr-professionals-role-buildingorganizational-success

Choi, M., and Ruona, W. (2011). Individual readiness for organizational change and its implications for human resource and organization development. Human Resource Development Review, 10 (1), 46-73

Eisenhardt, K. M. (1989). Building theories from case study research. Academy of Management Review, $14,532-550$.

Fredericks, J., and Stewart, J. (1996). The strategy-HRD connection. In Jim Stewart and Jim McGoldrick (Eds), Human resource development: Perspectives, strategies and practice (pp.101-119). Harlow, UK: FT Prentice Hall.

Garcia-Cabrera, A. M., and Hernandez, F. G-B. (2014). Differentiating the three components of resistance to change: The moderating effect of organization-based self-esteem on the employee involvement-resistance relation. Human Resource Development Quarterly, 25(4), 441-469.

Gold, J., Holden, R., Iles, J., Stewart, J. D., and Beardwell, J. (2009). Human resource development theory and practice. Basingstoke, UK: Palgrave-MacMillan.

Hamlin, R. G. (2001a). A review and synthesis of context and practice. In Bob Hamlin, Jane Keep, and Ken Ash (Eds.). Organizational change and development: A reflective guide for managers, trainers and developers (pp.13-38). Harlow, UK: FT Prentice Hall.

Hamlin, R. G. (2001b). Towards research-based organizational change and development. In Bob Hamlin, Jane Keep, and Ken Ash (Eds.). Organizational change and development: A reflective guide for managers, trainers and developers (pp.283-296). Harlow, UK: FT Prentice Hall.

Hamlin, R. G. (2002). Towards evidence-based HRD practice. In Jim McGoldrick, Jim Stewart, and Sandra Watson (Eds.) Understanding human resource development: A research-based approach (pp.93-121). London: Routledge.

Hamlin, R. G. (2007). Towards evidence-based management development. In Rosemary Hill and Jim Stewart (Eds) Management development: Perspectives from research and practice (pp.95-119). London: Routledge

Hamlin, R (Bob) G. (2015). Paradigms, philosophical prisms and pragmatism in HRD research. In Mark N. K. Saunders and Paul Tosey (Eds) Handbook of research methods on human resource development (pp.13-31). Cheltenham, UK: Edward Elgar

Hamlin, R. G., and Hatton, A. (2013). Toward a British taxonomy of perceived managerial and leadership effectiveness. Human Resource Development Quarterly, 24 (3), 365-406.

Hamlin, R (Bob) G., Keep, J., and Ash, K. (2001). Organizational change and development: A reflective guide for managers, trainers and developers. Harlow, UK: FT Prentice Hall.

Hamlin, R. G. and Reidy, M. (1997). Effecting change in management culture. Strategic Change Journal. $6(8), 435-450$.

Hamlin, R. G. and Reidy, M. (2005). Facilitating organizational change and development through professional researcher-practitioner partnerships ASTD International conference \& exposition Orlando, Florida, USA, June.

Hamlin, R. G., Reidy, M., and Stewart, J. (1998). Bridging the HRD research-practice gap through professional partnership. Human Resource Development International, 1 (3), 273-290.

Hamlin, R. G. and Sawyer, J. (2007) Developing effective leadership behaviours: The value of evidencebased management. Business Leadership Review, 4 (4).

Hamlin, R. G., Sawyer, J., and Sage, L. (2011). Perceived managerial and leadership effectiveness in a nonprofit organization: An exploratory and cross-sector comparative study. Human Resource Development International, 14 (2), 217-234.

Hatton, A. (2001). The complexity-clarity paradox. In Bob Hamlin, Jane Keep, and Ken Ash (Eds.). Organizational change and development: A reflective guide for managers, trainers and developers (pp.101-134). Harlow, UK: FT Prentice Hall.

Holton, E. F. (2004). Implementing evidence-based practice: Time for a national movement? Human Resource Development Review, 3 (3), 187-188. 
Jacobs, R. L. (1997). HRD partnerships for integrating HRD research and practice. In Richard A. Swanson, and Elwood F. Holton III (Eds.). Human resource development research handbook: Linking research and practice (pp.47-61). San Francisco, CA: Berrett- Koehler.

Kearns, P. (2014). Organizational learning \& development - From an evidence base. Abingdon, UK: Routledge. Kohut, A., and Roth, G. L. (2015). Change management. In R. F. Poell, T.S. Rocco, and G.L. Roth (Eds.), The Routledge companion to human resource development (pp.225-235). Abingdon, UK: Routledge.

Kuhn, T. (1996). The structure of scientific revolution (3rd ed.). Chicago: University of Chicago Press.

Latham, G. P. (2009). Becoming an evidence-based manager: Making the science of management work for you. Boston, MA: Davies-Black.

McKenzie, C., Garavan, T., and Carbery, R. (2012). Through the looking glass: Challenges human resource development (HRD) post the global financial crisis-business as usual? Human Resource Development International, 15 (3), 353-364.

Morgan, B. L. (2007). Paradigms lost and pragmatism regained: Methodological implications of combining qualitative and quantitative methods. Journal of Mixed Methods Research, 1, 48-76.

Patel, T., and Hamlin, R. G. (2012). Deducing a taxonomy of perceived managerial and leadership effectiveness: A comparative study of effective and ineffective behaviour across $3 \mathrm{EU}$ countries. Human Resource Development International, 15 (5), 571-587.

Pfeffer, J., and Sutton, R. I. (2006). Hard facts, dangerous half-truths \& total nonsense: Profiting from evidence-based management. Boston, MS: Harvard Business School Press.

Phillips, K., and Shaw, P. (1989). A consultancy approach for trainers. Aldershot, UK: Gower.

Rogers, P., Shannon, T., and Gent, S. (2003). Leading successful change. European Business Journal, 15, 104-111.

Rousseau, D. M. (2006). Is there such a thing as evidence-based management? Academy of Management Review, 31(2), 256-269.

Rousseau D. M. (2012). Envisioning evidence-based management. In D. M. Rousseau (Ed.), Handbook of evidence-based management. New York: Oxford University Press

Sadler-Smith, E. (2015). HRD research and design science. In Mark N. K. Saunders and Paul Tosey (Eds.) Handbook of research methods on human resource development (pp.32-44-31). Cheltenham, UK: Edward Elgar

Shook, L-V., and Roth, G. (2011). Downsizing, mergers, and acquisitions: Perspectives of human resource development practitioners. Journal of European Industrial Training, 35 (2), 135-153.

Stewart, J. (2015). Strategic HRD. In R. F. Poell, T. S. Rocco, and G. L. Roth (Eds.), The Routledge Companion to Human Resource Development (pp.203-211). Abingdon, UK: Routledge.

Stewart, J., and Hamlin, R. G. (1990). The management of change: What contribution can training make? Training and Development, August, 11-13.

Stewart J., and McGoldrick, J. (1996). Human resource development: Perspectives, strategies and practice. Harlow, UK: FT Prentice Hall.

Stewart, R. (1998). More art than science? Health Service Journal, 26, 28-29.

Szabla, D. B. (2007). A multidimensional view of resistance to organizational change: Exploring cognitive, emotional, and intentional responses to planned change across perceived change leadership strategies. Human Resource Development Quarterly, 18 (4), 525-558.

Thornhill, A., Lewis, P., Millmore, M., and Saunders, M. (2000). Managing change. Harlow, UK: FT Prentice Hall.

Tsang, E. K. K., and Kwan, K-M. (1999). Replication and theory development in organizational science: A critical realist perspective. Academy of Management Review, 24 (4), 759-780.

Ulrich, D. (1997). Human resource champions. Boston MA: Harvard Business School Press

van Aken, J. E. (2007). Design science and organization development interventions: Aligning business and humanistic values. The Journal of Applied Behavioral Science, 43 (1), 67-88.

van Aken, J. E. (2009) Reinventing the future: Adding design science to the repetoire of organization and management studies. Organization Management Journal, 6, pp.5-12.

Vince, R. (2008). "Learning-in-action" and "learning inaction": Advancing the theory and practice of critical action learning. Action Learning Research and Practice, 5 (2), 93-104.

Vince, R. (2014). What do HRD scholars and practitioners need to know about power, emotion and HRD? Human Resource Development Quarterly, 25(4), 409-420. 


\section{The Author}

Bob Hamlin is Emeritus Professor and Chair of Human Resource Development at the University of Wolverhampton, UK. His main research interest is exploring effective and ineffective managerial behaviour — including managerial coaching and mentoring effectiveness — as perceived by managers and employees within public, private, and third sector organizations. The results of his research have been published internationally in a broad range of management and HRD academic journals, and also in national practitioner publications. With various indigenous co-researchers he has replicated and continues to replicate his UK studies of perceived managerial and leadership effectiveness within a culturally diverse range of countries around the globe. His current aim is to use the results of these studies as empirical source data for conducting multiple case, cross-sector/cross-nation comparative analytic studies based on replication logic in search of empirical generalizations that might lead to new HRD related theory development.

\section{Acknowledgement}

This article has its origins in the author's chapters in Organizational Change and Development: A Reflective Guide for Managers, Trainers and Developers (Hamlin, Keep and Ash, Eds, 2001) and forms (with permission from the publishers FT Prentice Hall/Pearson) the foundation for a developed and extended chapter contribution to a forthcoming book Bridging the ScholarPractitioner Gap in Human Resources Development to be published by IGI Global. 